\title{
PREFACE
}

The 16th Annual Convention of the Japanese Association of Educational Psychology was held at Chiba University on September 25-27, 1974. The Chairman of the Convention was Prf. T. Takeuchi. Six hundred and fifty-four regular members, one hundred and twenty-four temporary members and fifty-one student members participated in the Convention. Three hundred and nine studies were presented by regular members in seven divisions: 1) Methodology, 2) Development, 3) Personality, 4) Social Psychology, 5) Learning, 6) Measurement and Evaluation, 7) Clinical Psychology. A bulletin containing the summaries of those studies was distributed to each member beforehand.

Three Separate symposia and an integrated symposium were conducted under the following titles :

Psychological tests and Education

Clinical tests and Education

Educational technology and Education

Educational. Psychology and Practice in Education

Their brief summaries are found in this volume.

\section{Integrated Symposium}

\section{EDUCATIONAL PRACTICE AND EDUCATIONAL PSYCHOLOGY}

\author{
Chairman: Sadao Nagashima (Saitama University) \\ Members : Tsuneo Yamashita (Ibaraki University) \\ Kaoru Yamaguchi (Tokyo Gakugei University) \\ Hiroshi Azuma (Tokyo University) \\ Jun Hosoya (Tohoku University) \\ Eiichi Yamashita (Kansai University)
}

In this General Symposium, the members were required to present their theoretical and practical views as to how educational psychology should be related to educational practices in schools and they were expected, if possible, to offer the suggestions about the ways in which educational psychology might be improved and advanced toward a more reliable science useful for teachers and educators.

Yamashita, T., Yamaguchi, K. and Azuma, H. who chaired Separate Symposia I., II. and III. respectively, presented their opinions reflecting and summarizing the major issues discussed in Separate Symposia. 